\title{
Allowing for MSD Prevention During Facilities Planning for a Public Service: An a Posteriori Analysis of 10 Library Design Projects
}

\author{
Marie Bellemare
}

Faculté des sciences sociales, Université Laval, Québec, Qué., Canada

\section{Louis Trudel}

Faculté de médecine, Université Laval, Québec, Qué., Canada

\section{Élise Ledoux}

Programme organisation du travail, Institut de recherche Robert Sauvé en santé et en sécurité du travail (IRSST), Montréal, Qué., Canada

\section{Sylvie Montreuil}

Faculté des sciences sociales, Université Laval, Québec, Qué., Canada

\section{Micheline Marier}

Université du Québec à Montréal, Montréal, Qué., Canada

\section{Marie Laberge}

Programme organisation du travail, Institut de recherche Robert Sauvé en santé et en sécurité du travail (IRSST), Montréal, Qué., Canada

\section{Patrick Vincent}

Association pour la santé et la sécurité du travail, secteur affaires municipales (APSAM), Montréal, Qué., Canada

Research was conducted to identify an ergonomics-based intervention model designed to factor in musculoskeletal disorder (MSD) prevention when library projects are being designed. The first stage of the research involved an a posteriori analysis of 10 recent redesign projects. The purpose of the analysis was to document perceptions about the attention given to MSD prevention measures over the course of a project on the part of 2 categories of employees: librarians responsible for such projects and personnel working in the libraries before and after changes. Subjects were interviewed in focus groups. Outcomes of the analysis can guide our ergonomic assessment of current situations and contribute to a better understanding of the way inclusion or improvement of prevention measures can support the workplace design process.

$$
\text { MSD prevention ergonomic design libraries }
$$

The authors would like to thank Estelle Viossat, an ergonomist, who collaborated with them in this study. The research was also made possible through a grant from the IRSST, the Robert-Sauvé Research Institute for Workplace Health and Safety and benefited from the support of APSAM, Quebec's joint sector-based (municipal affairs) association for occupational health and safety.

Correspondence and requests for offprints should be sent to Louis Trudel, Département de réadaptation, Faculté de médecine, Université Laval, Québec, Qué., Canada G1K 7P4. E-mail: <Louis.Trudel@rea.ulaval.ca>. 


\section{INTRODUCTION}

Library work mainly involves technologybased service functions. Library clerk positions are occupations where the likelihood of the development of musculoskeletal disorders (MSDs) is highest. Such positions involve almost constant demands on the musculoskeletal system and these demands are the source of a variety of MSDs affecting a high number of library employees.

Québec's joint sector-based association, APSAM $^{1}$, is called upon to deal with a high number of requests for interventions to reduce the incidence of MSDs in libraries. In some cases, the association receives such requests when employee complaints persist even after recent and costly workplace reengineering initiatives have been undertaken. This article presents data based on an a posteriori analysis of 10 library design or redesign projects that have already taken place. This first stage of a more wide-reaching research project had as its purpose: (a) to obtain the opinions of librarians responsible for the projects, and of their employees, as to hoped-for outcomes and what was done in the course of the projects to reduce the musculoskeletal impact of library work; (b) to identify markers for the design or transformation process on which to base MSD prevention; and (c) to use the a posteriori project analysis as a guide for the next two stages of the research, the first being an ergonomic analysis of current workplace practices among library clerks and the second, the provision of real-time backup for a design project.

In the first part of this article, a review of the literature confirms the importance of emphasizing prevention in this environment. The review is followed by a description of the qualitative methodology used and the results obtained. Our interpretation and discussion of the results led to the identification of reference markers that can be used in an ergonomic analysis of work practices and in an identification of support measures for MSD prevention in the design process.

\section{STATE OF SCIENTIFIC AND TECHNICAL KNOWLEDGE}

\subsection{The Incidence of MSDs Among Library Employees}

In 1998, there were estimated to be between 1,344 and 2,100 people employed in public libraries in Québec, Canada [1]. Laberge [2] found a high incidence of symptoms of MSDs in a sample of 406 respondents from Québec public libraries, $90 \%$ of whom had experienced symptoms in the course of the previous year. Of these employees, $80 \%$ associated their musculoskeletal symptoms with their workplace, $67 \%$ had consulted a health professional and $29 \%$ had needed to take time off work because of the symptoms. The back was the main area affected (68\% of respondents), followed by the upper limbs (64\%) and the neck area $(54 \%)$. Some $45 \%$ of respondents identified problems in the lower limbs. Tasks identified as likely to cause MSDs among employees included working with video display terminals, repetitive manual handling tasks and working in one position for long periods. When their results were compared with data on other kinds of work, different authors found that the incidence of pain experienced in the lumbar region, shoulders, wrists, neck and feet was more significant among library employees than among office workers in general. [3, 4, 5, 6, 7].

\subsection{Risk Factors for MSDs in Library Workplaces}

Frith and Hogg [7] have described the risks of the incidence of MSDs among staff working at the circulation desk of a university library. They observed that desk height and repeated manual handling of documents, plus the fact that employees often need to lean over, stretch out and twist around to take hold of books and register them, desensitize security codes and pass them back to users were all elements that constituted risk factors. For this kind of activity,

\footnotetext{
${ }^{1}$ This joint labour-management organization, the Association for Occupational Health and Safety in the Municipal Affairs Sector, was established under provisions of Québec's Workplace Health and Safety legislation. It provides workplaces in this sector with documentation and consulting services aimed at reducing the risks to which employees are exposed.
} 
Village, Campbell and Cull [6] showed that for each volume borrowed, more than 10 operations were required. Grey and Wilson [8] showed that inappropriate desk height, cramped space and poorly positioned equipment at the circulation desk made it difficult for employees to see or reach objects, thereby increasing musculoskeletal demands. Village, Campbell and Cull [6] also analyzed the importance of risk factors for employees responsible for shelving books. They found that these duties entailed significant repetitive effort, as carts loaded with documents were heavy and difficult to manoeuvre. Furthermore, employees often needed to support between 10 and $15 \mathrm{~kg}$ of documents with their non-dominant arm while checking for where exactly a document was to be placed or while carrying out the actual shelving. Each document returned by a user was handled approximately five times before it was shelved. Shelving also involved significant levels of visual attentiveness and cognitive demands to ensure that the order of volumes in collections was appropriately maintained.

Studies on MSD risk factors observed in library workplaces are primarily descriptive or plain-language articles documenting the presence of factors deriving from specific tasks. Indeed, although there is a significant body of literature on the correlation to be made between manual handling tasks and MSDs, only the studies by Village, Campbell and Cull [6] and by Blackburn, Girard and Lagacé [9] seem to have focused on this aspect of the disorder among library employees.

\subsection{The Challenges of Designing Ergonomic Layouts in Public Libraries}

In the recent resource allocation guide for public libraries published by the American Library Association (ALA) [10], ergonomics merits only scant attention and then only in relation to the comfort of users, rather than employees, or for purposes of library efficiency. The ALA document suggests readers consult the checklists and recommendations on ergonomics that can be found on the Internet.
Our survey of the literature did however find a few other publications pertaining to the physical layout and environment of libraries [11, 12, 13]. These documents are not based on analyses of work activity or on studies of risk-inducing factors. They rather constitute reference works summarizing a body of knowledge and making broad-based recommendations on the safe layout of work stations. The application of these recommendations becomes problematic when put in the context of the particular characteristics of a given library: special clientele, atypical buildings, specialized collections, available equipment, technologies used, etc.

The emphasis put on the physical layout in this kind of reference work seems to fail to take into account the overall organization of work, itself not a neutral factor as a potential source of MSDs. Village, Campbell and Cull [6] consider that organizational changes can reduce sources of stress observed in libraries. Examples that could have a preventive effect might be the assignment of shelving duties outside opening hours, using flexible work schedules, ensuring that bar codes are attached to documents so as to reduce the number of manual handling movements, or alternating document loan and return duties with shelving tasks.

\subsection{Implementation of New Technologies}

Huuhtanen, Vattulainen and Laamanen [14] documented the impact of the implementation of a new integrated library services system on management of loans and cataloging, tasks carried out, and workplace organization. Initially, respondents reacted favourably to the introduction of a new system, seeing it as an opportunity to better apply their skills, to experience increased flexibility in the division of work and to increase recognition of their professionalism. There were, however, concerns that they might find their work more monotonous and more repetitive. During the implementation phase, employees were generally satisfied with information they received about the changes. At the same time, they felt that they were given insufficient information on the future organization of their work, on changes to line-staff structures, on their own employment 
situation, on the economic situation of the library and on the way equipment worked. In addition, in the final stage of their review, the authors noted an increase in the rotation of duties (employees moved more rapidly from one task to another), in the number of rules to be followed, in the pace of work and in the degree of difficulty of tasks. It is fairly widely recognized that the technology component of the workplace can affect the development of certain MSDs, employee stress levels and the quality of services provided to users.

\subsection{Management of Projects in the Municipal Public Library Sector}

Three studies focusing on the use of ergonomic criteria describe approaches used, with support from employees, to implement changes in the workplace $[8,15,16]$. The approach Beaufort [16] tried out in a university library involved four phases to structure a change process where ergonomic elements were factored in (a) a definition of postulates based on the existing situation; (b) an analysis of the current work activity, centred on employee strategies; (c) an identification of reference markers, validated by employees using simulations of future work situations; and (d) an installation of equipment and follow-up adjustments. The Kensing and Madsen [15] study began by identifying reference sites, then moved into three work phases: (a) the critical phase: brainstorming on current problems; (b) the imaginative phase: brainstorming on solutions to resolve the problems identified in the critical phase; and (c) the implementation phase where the chosen solutions were applied and the technical specifications for their implementation were drawn up.

A document published by the American Library Association was produced to support decisionmaking for the implementation of change or for optimizing the use of the different resources to be found in public libraries [17]. Mayo and Goodrich described concrete approaches that to some extent took real work situations into account: assessment of real work carried out, performance evaluation, resource allocation analysis, process reengineering. The approach used recommended the creation of an employee advisory group to study the workload project. However, there were no specific recommendations for dealing with the physical layout or any changes that might be needed in this regard to increase efficiency or improve employee health and safety.

Overall, we do not have the knowledge base we need to assess the implementation of architectural projects in municipal public libraries. Yet this knowledge is fundamental if we are to determine directions for the prevention of MSDs in the design of library workplaces.

\section{METHODOLOGY}

Twelve libraries where new facilities or changes to facilities had been implemented in the past 2 years were asked to participate in this study. These libraries were selected on the basis of four diversification criteria: the nature and scope of the changes made, the size and regional base of the population served, the status of the establishment as a stand-alone or affiliated library, and the involvement, or lack of it, of a prevention professional (ergonomist, occupational health and safety [OHS] counsellor, industrial hygienist, etc.) in the change project. Ten libraries agreed to participate and each delegated the person responsible for the project and one employee representative. Two focus group interview meetings were organized, with 9 project leaders and 9 employee representatives in each, due to last-minute absences by participants from one library in each group. The interviews each lasted for approximately $3 \mathrm{hrs}$. The participants were encouraged to focus on their perceptions of the extent to which, as the projects progressed, due consideration was given to the nature of the work to be accomplished and ways to prevent MSDs, and to comment on their own involvement in the establishment of the layout design, as compared to that of other players.

Discussions were recorded and transcribed verbatim. An open-ended content analysis of the transcripts was then carried out using the method proposed by L'Écuyer [18, 19]. This approach is based on the identification of sub-themes and themes drawn from interviewee comments. 
When considered together, the themes and subthemes cover all the information collected. The two interviews were analyzed separately so as not to contaminate the development of themes between the two groups; the themes defined on the basis of each interview were then subjected to cross-analysis to allow for identification of areas of agreement and disagreement from one group to the other.

\section{RESULTS}

Content analysis of the discussions in each group and subsequent cross-analysis between the two enabled us to assign concerns to the following themes: work activities, physical environment, material used, organization of work, occupational health and the project process. Project leaders were more centred on the project process, material used and occupational health. The main difference between the two groups was to be found in the theme of the project process where project leaders, who claimed they were poorly prepared to take on this responsibility, expressed particular concern about the project start-up phase. This sub-theme will be discussed separately at the end of this section.

\subsection{Work Activities}

When commenting on work activity, interviewees stressed the demanding physical nature of this kind of work. Their comments can be closely linked to aspects of work activity that are common concerns of ergonomics and highlight MSD risk factors inherent in library work.

Clearly, all library design projects that want to take into account the work carried out and the prevention of MSDs must address such aspects of library activities as movement around the facility of individuals or carts, whether or not books are being transported; repetitive manual handling of documents, possibly aggravated by the use of technology-based tools; handling of heavy loads; document shelving involving particular physical demands; technology-driven relations with users; the use of document chutes, and situations where employees are required to stand, sit or remain partially seated for long periods.

The physical environment and the material used influence greatly the work activity and specific issues have been raised about them as Table 1 shows.

TABLE 1. Areas of Concern and Specific Issues Influencing Work Activity Which Were Raised by Participants

\begin{tabular}{lc}
\hline Areas of Concern & Specific Issues \\
\hline Physical environment & \\
Circulation desk & $\begin{array}{c}\text { Height, width, shape and } \\
\text { surface finish; need for } \\
\text { specifications during } \\
\text { design, for built-in } \\
\text { flexibility }\end{array}$ \\
$\begin{array}{c}\text { Space (e.g., for storing } \\
\text { book carts) }\end{array}$ & $\begin{array}{c}\text { Chronic shortages of } \\
\text { space in libraries: } \\
\text { more manual handling } \\
\text { needed }\end{array}$ \\
$\begin{array}{c}\text { Furniture, seats, stools } \\
\text { and footrests }\end{array}$ & $\begin{array}{c}\text { Careful selection to be } \\
\text { made }\end{array}$ \\
$\begin{array}{c}\text { Floor covering } \\
\text { Facilitating cart } \\
\text { movements, staff } \\
\text { standing and kneeling } \\
\text { for extensive periods }\end{array}$ \\
Ambiance in the facility \\
(ventilation, level of \\
noise, quality of lighting)
\end{tabular}$\quad \begin{gathered}\text { Influence well-being } \\
\end{gathered}$

\section{Equipment used}

\begin{tabular}{cc}
$\begin{array}{c}\text { Optical scanner, } \\
\text { sensitizing and } \\
\text { desensitizing devices, } \\
\text { computer screens, } \\
\text { mouse and keyboard }\end{array}$ & $\begin{array}{c}\text { Compatible with service } \\
\text { to users; need to } \\
\text { anticipate evolution of } \\
\text { technology }\end{array}$ \\
$\begin{array}{c}\text { Outside and inside book } \\
\text { chutes }\end{array}$ & $\begin{array}{l}\text { Need to reduce } \\
\text { physical demands } \\
\text { when documents are } \\
\text { removed from book } \\
\text { containers }\end{array}$ \\
$\begin{array}{c}\text { Display stand and book } \\
\text { separators }\end{array}$ & $\begin{array}{c}\text { Need to buy good quality } \\
\text { material due to heavy } \\
\text { levels of use }\end{array}$ \\
\hline
\end{tabular}

\subsection{Organization of Work}

The joint interviews clearly show how choices made about the organization of work directly influence work activity. Such choices are sometimes made at the macromanagement level and sometimes at the day-to-day level. They are very closely linked to architectural choices (type 
of building and space available) and to the kind of services offered (clientele served, opening hours, nature and size of collections, reference services, Internet stations, etc.).

The main organizational choices identified by participants as being determinants of work activity were the status of the library as a stand-alone or affiliated facility, available staff resources, use of technology, the number of documents users can borrow, the existence, or lack, of document return chutes to reduce overcrowding at the circulation desk, duties assigned to each work station, rotation of work stations, proximity of book carts to the work area handling returns, and whether user access to audiovisual and multimedia documents was direct or required the services of an employee. Participants also stressed that, although many computer-based and electronic tools were supposed to make it easier to do more with fewer human resources, there was need for prudence in choosing to rely on technology; they were far from convinced that it could make up for needed human resources. Interviewees observed that technology in fact accelerated the rhythm of work. They maintained that document handling volumes had increased, in particular because anti-theft systems meant that documents had to be passed in front of sensitizers and desensitizers and that computerization usually coincided with an increase in the number of documents users could borrow. This increase in the number of documents in the lending and returns chain would offset any supposed gains achieved through computerization of document handling.

Employees felt that it would be useful to have opportunities to regularly discuss the organizational challenges encountered in their work with a view to identifying solutions adapted to the rapidly changing nature of their work.

\subsection{Health}

Participants interviewed stated that MSDs or other health problems were often the starting point of changes for which specialists in OHS, in ergonomics, or other preventionists needed to be consulted. At the same time, the connection between MSDs and work activity was always believed to require tangible proof and was the target of much suspicion. Certainly, compensation for occupational health disorders seemed to be extremely rare. Participants stressed the fact that physical demands seemed to be increasing, particularly due to the increase in manual handling of documents generated by some technology choices, and by the extra book box handling requirements that stemmed from the way a central library with service centres was organized. Many respondents found that they did not have the energy needed for domestic and recreational activities after work hours.

The main prevention elements identified by participants were clearly consistent with the problems they identified. Interviewees suggested, e.g., that particular attention be paid to how often duties were rotated at different work stations, to the need for sufficient staff at busy service periods, to the quality of electronic instruments and equipment, to encouraging the occasional provision of assistance to a fellow employee for certain tasks (like pushing a heavy cart together), to positioning bar codes where they could most easily be read and so reduce the number of document handling movements, and to making it easier to scan documents at well-placed builtin equipment. Training given by organizations responsible for prevention in OHS or by other interveners about postural hygiene, lifting of heavy objects and safe physical movements were seen as being useful prevention activities.

In terms of health protection, project leaders expressed particular concern about the challenge of changing employee habits or ways of carrying out their duties. They believed that these habits were solidly ingrained and were extremely difficult to change even if the ultimate objective was to improve employee health.

\subsection{The Project Process}

Seven different elements were identified in this regard. The first was employee consultation on which employees and project leaders were unanimous in their comments. All participants felt that the architects involved, and, to an equal extent, those with ultimate responsibility for a project $^{2}$, should take their recommendations and opinions into account during project 
implementation and inform them about the nature of any planned changes. This point led naturally into the next: collaboration over the course of the project. In this case, employees and internal project leaders agreed that their participation throughout the various phases of the project was highly important, not solely at the outset. In one of the libraries, the experience was extremely positive: "the architect proposed ideas for the design and we [the employees] were able to validate them, and we really got what we wanted"3. This approach can be ascribed to the way that the architect worked; no ergonomist was involved in the project. In some libraries (where an ergonomist participated in the project design), collaboration was indeed part of the process, but the process itself was further improved by the creation of a committee of which both the project leader and, in several cases, an employee were members ("the most senior of our lending clerks was a member of the committee, along with the architect, the city's HR (human resources) specialist, and myself [the project leader]). We all participated as equals and we had the opportunity to really express our needs"). Another positive element identified by interviewees during the two group meetings was the use of models or mock-ups. Models were used for two of the library projects and both the employees and the project leaders involved expressed their satisfaction with this approach. One of the other libraries used simulations, in a separate room.

\subsection{Other Aspects of Project Process Sub-Themes Raised Only by Project Leaders}

The themes of the starting point for a project, project funding, and interactions with public services and experts were raised only by the project leaders. Whether it was in the context of an extension, a move to new or renovated premises or even changes in layout needed as a result of threats by the CSST (Commission de la santé et de la sécurité au travail, the body responsible in Québec for OHS) to close down the circulation desk, the CSST's role in helping to move projects forward was seen as positive. In fact, the intervention of the CSST was flagged as a contributory factor in obtaining the collaboration of other external organizations involved in prevention, and in attracting the attention of administrators and public works services of the cities involved. When numerous cases of occupational illnesses or accidents are declared, the rates employers have to pay for collective OHS insurance rise, and this increases their motivation to correct problem situations.

In particular, the joint sector-based association dealing with OHS in libraries can become involved in a project by offering the services of a professional specializing in library redesign. A report produced by an external expert reinforces the credibility of a library manager in the eyes of municipal authorities, and also usually leads to the inclusion of library employees in the process. When this is the case, library managers and their employees are in a position to better understand the complexity of the project and the workings of the system they will be involved with. Staff members also come to realize that library managers in their turn are not always able to do what they themselves want to do.

On several occasions, participants made the point that the low importance attached by mayors to library staff working conditions was a recurrent problem during the facilities planning process. Elected officials give far more weight to issues affecting users, accessibility, and the aesthetics of the facility ("because you can see things like that, whereas the working conditions of the people inside don't carry enough weight to affect those people's potential re-election"). Some participants went so far as to suggest the need for legislative or regulatory provisions to ensure that a given percentage of a building or renovations budget be used for the services of an ergonomist, to oblige decision-makers to recognize the existence of such issues.

\footnotetext{
${ }^{2}$ In most cases, this meant the city administration.

${ }^{3}$ The quotations in the text are extracted from the verbatim transcripts of the interviews with the participants to illustrate some of their concerns.
} 
Overall, this synopsis of the experiences of 10 different library projects provides us with several elements that enhance our understanding of the connections between work activity, the prevention of MSDs and the project process.

\section{INTERPRETATION AND DISCUSSION}

\subsection{Two Types of Project to Analyze: The Utilitarian Approach and the Creative Approach}

Analysis of the interviews revealed that the project process was a source of major concern for its impact on project outcomes. Library managers found the role of project leader for a renovation or building project to be a responsibility for which they were not necessarily prepared and a situation where they could be trapped between conflicting points of view. A facilities design project has to take a high number of issues into account and not all of them carry the same weight.

For prevention purposes, it would seem that two different types of projects can be identified. In the first case, these are projects based on a diagnosis of health problems arising from poor facilities layout or inadequate equipment. This leads to what we would call a utilitarian project approach, designed to address a specific problem and thus putting the overall focus on workplace issues. In the second type of project, work activity is not in itself a factor but does need to be incorporated into the overall concept. This kind of approach can be qualified as creative because it involves creating an environment where a range of issues, that may or may not include work activity, need to be addressed or readdressed. It will be interesting to compare, as our research progresses, the emphasis put on prevention in the way the two types of project evolve. Our assumption is that strategic support measures will need to be identified in the creative approach to successfully address workplace activity issues as a project progresses.

\subsection{Decisions During a Project That Influence Work Activity}

In ergonomics, real work activity is considered to be a compromise between what needs to be done and the means to do it [20]. This means that work activity can be analyzed in relation to a certain number of determinants that condition it, at least in part.

Some of these determinants, known as microdeterminants, are immediate and can be found in close proximity to work situations; others, on the contrary, are found at a distance from work situations, occur prior to work activity, although they do influence it, and can be described as macrodeterminants [21]. In both cases, they require the identification of specific support measures that can be used as targets for action in the course of a project.

\subsubsection{Microdeterminants}

The kind of furnishings used for circulation desks, seats, stools, footrests, document return containers, book stacks and carts all seem to be microdeterminants for work activity. Kuorinka and Forcier [22] found that it was their particular characteristics that determined whether or not they would constitute risk factors for upper body MSD, if, e.g., they did or did not require sustained effort, awkward positions, or physical pressure. These risk factors can be observed during work activity and it is possible to take steps to reduce their impact by changing their intensity or frequency, or the duration of rest breaks. The impact of awkward positions at a circulation desk can, e.g., be reduced by installing equipment that allows employees to make fewer potentially harmful movements. In fact, staff members may themselves have developed strategies to minimize health risks. They might, e.g., slide books along a counter to avoid lifting them. Unfortunately, if the counter surface is made up of different levels, this strategy cannot be applied. Another example would be a desensitizer that requires strong pressure on the document to successfully function, thereby increasing risk factors associated with the document handling activity. Over the course of a design project, efforts need 
to be made to minimize the presence of risk factors by targeting microdeterminants such as furnishings, equipment and tools that create the context of the work situation. Observation of the work activity carried out can also be used to draw attention to individual and collective strategies that help reduce exposure to MSD risk factors.

\subsubsection{Macrodeterminants}

Macrodeterminants of the activity result from choices made well upstream in the project process. While such choices are made at a distance from the work environment, these are factors that contribute, at least in part, to defining the activity that will take place at work stations. They include the architecture of a facility, the choice of services and the organization of work.

In considering the architecture of a facility, the shape and number of stories in the building, floor space assigned to collections and the existence of sloping surfaces all have an influence on work activity.

When service choices are made, a library facility that is transformed into a service centre will become a place where boxes of books transit in large numbers, so there needs to be provision for special box handling measures to avoid adverse effects on employees. The decision to install an electronic theft-proofing system will result in particular handling movements when documents are borrowed or returned. Decisions about opening hours or the number of documents users may borrow are further examples of service choices that directly impact on work activity.

In the organization of work, the availability of staff resources, and rotation among various work stations or assignment of duties can be quite significant factors in their influence on work activity.

For every step of a project, the best way to support MSD prevention in the workplace is by establishing a framework that takes into account the potential impact on work activity of the various choices being envisaged as regards services to offer, space availability and organization of work. Although the choices made in these different areas are interrelated, they need to be considered separately at the time of a decision because they come under the responsibility of different players and it is these different players who must be dealt with if they are to influence the desired direction of choices that benefit work activity.

\subsection{Involvement of Many Players in a Project}

As participants pointed out, there are a large number of players involved in a library design project, including project managers, mayors, architects, engineers, designers, HR managers, builders, etc. Through the choices they make, each one plays a role in the creation of future work situations. The project leaders, usually the librarians involved, find themselves constantly buffeted between the different and often contradictory points of view they favour. When the services of an expert in prevention are called for, they may well be torn between pressures from the building experts and the prevention expert. This latter resource becomes a new player to be included in discussions and will potentially be seen by some others as a troublemaker.

In addition to needing to focus attention on concerns about work that will be carried out in the future and participating in discussions with other players, the work activity expert also needs to address a particular issue raised by participants. The interviews clearly showed the need for ergonomists to make precise recommendations, and even to provide specifications for such things as the layout of work stations, specifications that leave no room for interpretation. In fact, current trends in ergonomic analysis of activities suggest that relevant information needs to be provided to designers using a kind of job-shadowing approach that means recommendations can be adapted to the design situation, since the design itself is always evolving. Designers constantly need to make compromises and excessively rigid recommendations would probably negatively affect how they factor work activity into their plans. The participants we interviewed argued that, because of the short time-frame for introducing changes, negative effects could best be avoided, without disrupting service, by reference to very precise specifications. However, 
it would perhaps be possible to avoid disruption of service by carrying out simulations on fullscale mock-ups, in different rooms or premises.

\subsection{Employee Involvement: From Enthusiasm to Disappointment}

Another major issue raised in the interviews was the high importance attached to employee involvement in projects. For library staff, changing their work environment equates to changing the ways they work, with all the potential problems that can cause. Library managers see involvement of employees as a valuable way of working with them to define the future organization of their workplace. For their part, employees who had been through the experience of consultation, although they wanted to participate on a regular basis as projects progressed, told interviewers of difficulties they had experienced in reading and understanding plans. They would find three-dimensional mockups or prototypes much easier to use to grasp the implications of future work situations. In spite of the problems employee involvement may sometimes create, it would be difficult to avoid using this approach in any project that wants to put major emphasis on work activity.

\section{CONCLUSION}

The a posteriori analysis of library renovation or building projects proved to be a valuable tool for giving direction to the overall research we are carrying out. It enabled us to identify work activity issues that needed to be taken into account over the course of such projects. Consideration of these issues needs to factor in both the microdeterminants that allow for the modelling of activity-related risk factors and the macrodeterminants that help us understand how major project decisions influence these microdeterminants. If serious consideration is not given to work activity issues at all stages of a project, microdeterminants risk becoming permanently entrenched. This might help explain why some recent redesign projects continue to be the subject of employee complaints or dissatisfaction. Furthermore, the analysis also illustrated a number of ways work activity issues could be tangibly addressed through interaction in a project between players with shared or differing goals.

\section{REFERENCES}

1. Ministère de la Culture et des Communications. Bibliothèques publiques-statistiques 1997. Québec, Qué., Canada: Gouvernement du Québec; 1999.

2. Laberge M. Enquête exploratoire: problèmes musculo-squelettiques, accidents et conditions de travail chez les commis de bibliothèque. Montréal, Qué., Canada: Association for Occupational Health and Safety in the Municipal Affairs Sector (APSAM); 2000.

3. Bunker EM, Horrigan KR, Whiting JF. Interactive design of cataloguers workstation. In: Adams AS, Hall RR, McPhee BJ, Oxenburgh MS, editors. Proceedings of the 10th Congress of the International Ergonomics Association, Sydney, Australia. Sydney, Australia: Ergonomics Society of Australia; 1988. p. 69-71.

4. Smith RT. Case study of a library worker with leg and back injuries. In: Proceedings of the 23rd Annual Conference of the Human Factors Association of Canada. Ottawa, Ont., Canada: Human Factors Association of Canada; 1990. p. 243-6.

5. Baud D. Métier: bibliothécaire; complexité et servitudes. Arch Mal Prof. 1992;53(1): 47-8.

6. Village J, Campbell B, Cull J. Ergonomic analysis of materials handling and design guidelines for a new central public library. In: Innovations for InteractionsProceedings of the Human Factors Society 36th Annual Meeting. Atlanta, GA., USA: Human Factors Society; 1992. p. 1148-52.

7. Frith J, Hogg L. The application of library guidelines: a participative approach to the design of key library facilities. In: Ergonomics-Enhancing Human Performance, Proceedings of the 32nd Annual Ergonomics Society of Australia and the Safety Institute of Australia National Conference, Canberra, Australia: Ergonomics Society of Australia; 1996. 
8. Grey SM, Wilson JR. Libraries: fertile ground for ergonomics. In: Brown ID, Goldsmith R, Coombes K, Sinclair MA, editors. Proceedings of the 9th Congress of the International Ergonomics Association, Bournemouth, UK. London, UK: Taylor \& Francis; 1985. p. 403-5.

9. Blackburn P, Girard M, Lagacé PP. Analyse biomécanique chez des commis au reclassement des documents d'une bibliothèque. Travail et Santé. 2001;17(4): S21-3.

10. Nelson S, Altman E, Mayo D. Managing for results: effective resource allocation for public libraries. Chicago, IL, USA: American Library Association; 2000.

11. Bube JL. The ergonomics/human factors approach to health sciences libraries. Bull Med Libr Assoc. 1985;73(3):254-58.

12. Morris A, Dyer H. Human aspects of library automation. 2nd ed. Aldershot, UK: Gower; 1998.

13. New Zealand Library and Information Association. Health and safety issues in New Zealand libraries. Wellington, New Zealand: New Zealand Library and Information Association; 1998.

14. Huuhtanen P, Vattulainen M, Laamanen I. Communication - a key factor in the implementation of library automation. In: Smith MJ, Salvendy G, editors. Human-computer interaction: applications and case studies. Amsterdam, The Netherlands: Elsevier; 1993. p. $976-81$.
15. Kensing F, Madsen KH. Generating visions: future workshops and metaphorical design. In: Greenbaum J, Kyng M, editors. Design at work: cooperative design of computer systems. Hillsdale, NJ, USA: Erlbaum; 1991. p. 155-68.

16. Beaufort, P. L'ergonomie cognitive à la bibliothèque de l'Université Laval. Travail et santé. 1994;10(1):5-9.

17. Mayo D, Goodrich. Staffing for results: a guide to working smarter. Chicago, IL, USA: American Library Association; 2002.

18. L'Écuyer R. L'analyse de contenu: notions et étapes. In: Deslauriers J-P, editor. Les méthodes de la recherche qualitative. Sillery, Qué., Canada: Presses de l'Université du Québec; 1987. p. 49-65.

19. L'Écuyer R. Méthodologie de l'analyse développementale de contenu, méthode GPS (Genèse des perceptions de soi) et concept de soi. Sillery, Qué., Canada: Presses de l'Université du Québec; 1990.

20. Guérin F, Laville A, Daniellou F, Duraffourg J, Kerguelen, A. Comprendre le travail pour le transformer: la pratique de l'ergonomie. 2nd ed. Montrouge, France: Agence nationale pour l'amélioration des conditions de travail (ANACT); 1997.

21. Villeneuve J. PARC: des fondations solides pour un projet de rénovation ou de construction. Objectif Prévention. 1994;17(5):19-25.

22. Kuorinka I, Forcier L, editors. Work related musculoskeletal disorders (WMSDs). A reference book for prevention. London, UK: Taylor \& Francis; 1995. 